\title{
LA DESPERSONALIZACIÓN COMO METAFÍSICA VIVENCIAL DE LA VOLUNTAD DE VIVIR
}

\author{
Sandra Baquedano Jer* \\ Universidad de Chile \\ sandra.baquedano@uchile.cl
}

\begin{abstract}
Resumen
Este artículo sobre la despersonalización como metafísica vivencial de la voluntad de vivir deja de manifiesto que a través de fenómenos asociados a la despersonalización es posible vivenciar que no solo somos sujetos cognoscentes, sino que también en nuestra interioridad somos cosa en sí. A partir de esta vivencia sondearemos la posibilidad de hacernos autoconscientes de aquel noúmeno volente para captar la esencia íntima de las cosas, encarando a la voluntad, es decir, enfrentándose a uno mismo. He aquí cuando la voluntad de vivir sale de su anonimato, encuentra su identidad y comienza el curso de su negación.
\end{abstract}

Palabras Clave: despersonalización, órgano de los sueños, voluntad de vivir, negación de la voluntad de vivir, sabidurías de oriente, intuición intelectual, clara y distinta, sufrimiento.

\section{Abstract}

This article is about depersonalization as existential metaphysics of the will to live, stating that through phenomena associated with depersonalization it is possible to experience that not only are we knowing beings, but we are also things-in-itself in our interiors. From this experience, we will explore the possibility of becoming independently conscious from that noumenon of will, to capture the intimate essence of things, facing the will, which means, facing oneself. This is when the will to live stops being anonymous, finds its identity and begins the path of its denial.

KEYwords: depersonalization, dream organ, will to live, denial of the will to live, Oriental wisdom, intelectual intuition, clear and distinct, suffering.

R⿴囗十 "A mis diecisiete años, sin haber terminado la formación escolar, fui sobrecogido por la desolación de la vida, igual como le ocurrió a Buda en su juventud, cuando observó la enfermedad, la vejez, el dolor y la muerte. La verdad, clara y distinta que me habló del mundo, se sobrepuso a los dogmas judaicos que me habían inculcado y mi conclusión fue que este mundo no podía haber sido la obra de un ser benévolo, sino más bien de un diablo que llamó a las criaturas a la existencia para recrearse en la contemplación de su dolor. Esto me señalaban los datos, y la creencia de que era así, se impuso. Sin duda, la existencia humana proclama el destino del sufrimiento: pues está profundamente inmersa en el sufrimiento, no se salva de éste, su

Este artículo forma parte de los proyectos FONDECYT 3085001 y SOC 09/14-2. 
curso y desenlace es sin excepción trágico: una cierta intencionalidad no es aquí algo para subestimar. Sin embargo, ahora es el sufrimiento el $\delta \varepsilon v ́ \tau \varepsilon \rho \circ \varsigma \pi \lambda$ oũ $\varsigma$, el surrogato de la virtud y la santidad. Como purificado de eso se alcanza finalmente la negación de la voluntad de vivir, el retorno del extravío a la redención: pues esa es la fuerza misteriosa que conduce nuestro destino (...) No obstante, esta fuerza y omnipotencia misteriosa es nuestra propia voluntad. Mas este punto de vista no entraba en nuestra conciencia, como ya he explicado detalladamente, y entonces el sufrimiento era ciertamente en primer lugar la meta de la vida, al igual como si fuera la obra de un diablo. Sin embargo, esta meta no es lo último, es sólo un medio singular, un instrumento de la gracia, para conseguir por nosotros mismos el verdadero y último bien" (Schopenhauer 1985 Tomo IV-1, p. 96).

Un testimonio autobiográfico traslada retrospectivamente al filósofo de 44 años a la vivencia de un joven de 17, que aún sin terminar su formación escolar, fue sobrecogido por la desolación de la vida. Schopenhauer recogerá en un pasaje de su obra capital la observación de Helvétius, para corroborar su tesis, de que todas las grandes concepciones verdaderamente originales que sea capaz de formular un hombre eminente son resultado de las impresiones existenciales de la primera juventud (1986, Tomo II, p. 108). Estas concepciones primeras no son meros encadenamientos de nociones abstractas, sino la comprensión profunda e intuitiva del mundo objetivo. Las obras escritas más tarde suelen ser meros arreglos, aplicaciones y desarrollos de dichas vivencias (1986, Tomo II, p. 97). La madurez intelectual aunada con estas meditaciones posteriores permite aclarar lo que se ha percibido y adquirir muchos más conocimientos con los cuales poder ensanchar el horizonte, rectificar y darle finalmente sentido a las experiencias diáfanas de juventud, desprotegidas de fortificaciones abstracto-intelectuales y recursos teóricos (1986, Tomo IV, p. 570). En este sentido podríamos decir que Schopenhauer fue sobrecogido por la desolación de la vida antes de tomar los problemas de los libros. De este hecho se desprenden aspectos fundamentales de su pensamiento, aquello que le permite desarrollar lo más propio y original de él. "La intuición no es sólo la fuente de todo conocimiento; es también el conocimiento $\kappa \alpha \tau^{\prime} \dot{\epsilon} \xi o \chi \eta ่ v$, el conocimiento verdadero, el único que merece en realidad ese nombre, pues es el que nos da el discernimiento de las cosas; el que el hombre puede realmente asimilarse, aquel de que puede penetrarse hasta lo más profundo de su ser, y que tiene el derecho de considerar como suyo" (1986, Tomo II. p. 103). La intuición (Anschauung) puede aludir a dos de sus formas, pero en cualquier caso se encuentra en oposición al conocimiento abstracto, discursivo y conceptual propio de la razón. Dentro de la intuición es especialmente importante la intuición intelectual (die intellektuale Anschauung), que es un conocimiento llevado a cabo por el entendimiento, concretamente, el conocimiento intuitivo de la realidad empírica que se produce por la aplicación de la ley de la causalidad (Gesetz der Kausalität) a los datos sensibles (1986, Tomo III. p. 61).

Schopenhauer considera que la intelectualidad de la intuición es principalmente obra del entendimiento (Verstand). Éste mediante la causalidad (Kausalität) que le es propia y la forma (Form) sometida a ella de la sensibilidad pura (reine Sinnlichkeit), esto es, tiempo y espacio, crea y hace -cual artista que fuera- de la materia (Stoff) de unas pocas sensaciones (Empfindungen) que están en los órganos de nuestro cuerpo, 
el mundo exterior objetivo (objektive Außenwelt). A diferencia de Kant, la sensación (Empfindung) -sea cual fuere su especie-, es en todos los casos un proceso que tiene lugar dentro de nuestro organismo y, por lo tanto, no contiene nada que resida fuera de nosotros. La sensación puede ser agradable o desagradable, lo cual manifiesta una subordinación a la voluntad, pero no hay propiamente objetividad en nuestras sensaciones, puesto que -según Schopenhauer- ellas son algo esencialmente subjetivo, cuyas mutaciones llegan a nuestra conciencia en la forma del sentido interior (innern Sinnes), es decir, en la forma del tiempo. Ahora bien, solo cuando el entendimiento (Verstand) entra en actividad, aplicando la ley de causalidad, se opera una transformación decisiva, porque de la sensación subjetiva (subjektiven Empfindung) se hace la intuición objetiva (objektive Anschauung). "En virtud de su forma peculiar, y por tanto a priori, esto es, anteriormente a toda experiencia (pues ésta no es hasta ahora todavía posible), el entendimiento aprehende la dada sensación del cuerpo como un efecto (palabra que él sólo entiende), efecto que como tal debe tener necesariamente una causa. Al mismo tiempo llama en su auxilio a la forma del sentido exterior, que reside igualmente predispuesta en el intelecto, esto es, en el cerebro: el espacio, para colocar dicha causa fuera del organismo: pues sólo de este modo nace para él lo exterior, lo de fuera, cuya posibilidad es precisamente el espacio; así es que la pura intuición a priori es la que debe suministrar la base de la intuición empírica" (1986, Tomo III, p. 69). Lo que queda de manifiesto en este proceso es que el entendimiento toma de la sensación dada (gegebenen Empfindungen), todos los datos (Data), por más ínfimos que sean, para construir en el espacio, con arreglo a ellos, la causa (die Ursache) de dicha sensación. Sin embargo, estos datos no proporcionan todavía ninguna intuición, porque esta última pertenece al entendimiento (Verstand). Pese a ello, debe tenerse en cuenta aquí, que esta operación del entendimiento no es una operación discursiva que realiza in abstracto, es decir, mediante conceptos y palabras, sino una operación intuitiva y completamente inmediata. Mediante ésta se llena el espacio en sus tres dimensiones que después varía en el tiempo con arreglo a la misma ley de la causalidad. "Según esto, el entendimiento tiene que crear el mismo ese mundo objetivo: y no puede, como si estuviera ya prefabricado, meterlo en la cabeza por medio de los sentidos y de las puertas de sus órganos. Pues los sentidos no suministran más que la materia bruta que antes que nada el entendimiento, por medio de las indicadas formas simples: espacio, tiempo y causalidad, transforma en la concepción objetiva de un mundo corpóreo regido por leyes. Conforme a esto, nuestra intuición ordinaria, empírica, es una intuición intelectual"' (1986, Tomo III, pp. 69-70). Lo anterior implica que tanto el tiempo como el espacio y la causalidad no proceden del exterior mediante la vista, el oído, el tacto, sino que por el contrario tienen un origen interior y por eso mismo no es empírico, sino intelectual. Esto permite desprender que la intuición del mundo corpóreo, es en esencia un proceso intelectual, una obra del entendimiento, reconociendo que la sensación de los sentidos proporciona la ocasión y los datos para la aplicación de los casos particulares. De esta manera, el idealismo trascendental schopenhaueriano es más radical que el kantiano, ya que identifica el dato empírico con la sensación subjetiva que se produce como un sentimiento dentro del organismo. Con lo ya ganado, es posible reconocer que las nociones toman su sustancia del conocimiento intuitivo y que además el mundo del pensamiento descansa por entero 
sobre el mundo de la intuición. "Las intuiciones suministran la sustancia real de todos nuestros pensamientos, y cuando ellas faltan no queda en nuestro espíritu más que nociones y palabras" (1986, Tomo II, p. 96). La ausencia de la intuición hace que las nociones de una cosa proporcionen solo un conocimiento general, formal o abstracto. "Los libros no suplen la experiencia ni el saber suple el genio: la razón común de estos dos fenómenos conexos es, que lo abstracto no puede reemplazar a lo intuitivo. Los libros no pueden suplir la experiencia, porque los conceptos permanecen siempre en la esfera de lo general, sin descender nunca a lo particular, que es de lo que se trata la vida" (1986, Tomo II, p. 100). Precisamente de este hecho se desprende que la filosofía no debe operar sobre conceptos, sino con conceptos, es decir, debe depositar sus resultados en nociones abstractas, pero no tomar éstas como datos o puntos de partida: "la intuición es para nuestra inteligencia lo que el terreno sólido para nuestro cuerpo. Cuando se abandona el terreno de la intuición, todo se convierte en instabilis tellus, innabilis unda" (1986, Tomo II, p. 118). La mera noción de algo, las puras nociones de las cosas, sin la intuición, proporcionan -desde esta perspectiva- solo un conocimiento general, no dando cabida a una comprensión sólida y profunda.

He señalado que Schopenhauer realiza una interpretación personal del idealismo kantiano, enfatizando que nuestra intuición del mundo externo no es meramente sensual, sino ante todo intelectual, es decir, cerebral ${ }^{1}$. "Los sentidos nunca proporcionan más que una mera sensación en un órgano, por tanto una materia muy pobre en sí misma, a partir de la cual el entendimiento construye ese mundo corporal en primer lugar, mediante el uso de la ley de la causalidad, por él conocida a priori, y de las formas, que existen en él también a priori, el espacio y el tiempo. En el estado de vigilia y normal, el estímulo para estos actos de intuición procede, por supuesto, de la sensación, a la que el entendimiento señala como causa" (1986, Tomo IV, p. 276). El mundo real, la conciencia empírica cambia permanentemente, en cuanto es consecuencia de otro cambio anterior, es decir, su causa. En este sentido, la producción de todo pensamiento y representación en la conciencia está sometida, en general, al principio de razón suficiente. Sin embargo, ocurre que en ciertas ocasiones de "otro lado" (1986, Tomo IV, p. 276), por consiguiente, del interior del organismo llega un estímulo al cerebro y es elaborado por éste del mismo modo que uno exterior, mediante su función propia y autónoma.

Schopenhauer se vale de la denominación "órgano de los sueños" -el cual no es un órgano físico, sino una metáfora- para designar a la capacidad de intuición, que

1 En relación con ello consúltese además el Tomo IV: "Skizze einer Geschichte der Lehre vom Idealen und Realen"; Tomo III: "Über das Sehn und die Farben”; Tomo II, p. 33 (En este último escrito aclara Schopenhauer: "Aunque desconozca por completo a Kant, Reid suministra, siguiendo la regla de lo necesariamente falso (regula falsi), una prueba indirecta de la intelectualidad de la intuición (que yo he sido el primero en demostrar siguiendo la doctrina kantiana) y del origen apriórico descubierto por Kant de sus ingredientes fundamentales, o sea, del espacio, del tiempo y de la causalidad”. El filósofo alude con esto a Thomas Reid y su libro Inquiry into the human mind). 
"es independiente de la percepción externa de los sentidos" (1986, Tomo IV, p. 289). Si se tiene una visión de la realidad sin las habituales impresiones externas, ocurre que la realidad es soñada, lo que es posible en la medida en que: "aquel ojo, con el cual vemos en los sueños, puede también una vez abrirse en la vigilia" (1986, Tomo IV, p. 329).

Visiones representan para Schopenhauer de un modo esencial algo real o se refieren a sucesos futuros mientras que las meras alucinaciones "se corresponden a los sueños normales carentes de significado" (1986, Tomo IV, p. 336). Visiones de todo tipo, las cuales con el resto de las apariencias se relacionan con el "órgano de los sueños" son: "fenómenos emparentados, ramas de un mismo tronco, y proporcionan indicios ciertos e irrefutables de un nexo entre los seres que reposa sobre un orden totalmente diferente de cosas al de la naturaleza, cuya base está formada por las leyes del espacio, el tiempo y la causalidad. Puesto que aquel otro orden es más profundo, primordial e inmediato, ante él las leyes primeras y más generales de la naturaleza, al ser puramente formales, no son válidas. El tiempo y el espacio ya no separan a los individuos, y su separación y aislamiento, que precisamente descansan sobre esas formas, ya no interponen barreras infranqueables a la comunicación del pensamiento y a la influencia directa de la voluntad, de suerte que los cambios se efectúan de un modo totalmente diferente al de la causalidad física y de las cadenas continuas de sus miembros, esto es, sólo gracias a un acto de la voluntad que se muestra de una manera especial y que se eleva por encima del individuo" (1986, Tomo IV, p. 319).

Puesto que el conocimiento mismo propio de la conciencia empírica está subordinado al principio de razón, no puede penetrar en la esencia interior de las cosas. Con otras palabras, el conocimiento empírico no posibilita ningún camino rumbo a la esencialidad y, por consiguiente, el logro de una conciencia mejor. Aquella vivencia que posibilita más tarde el descubrimiento y la asimilación de la voluntad como la cosa en sí. De la ilusión en la que está inmersa la conciencia empírica no es posible liberarse, en cuanto: "nuestra capacidad cognoscitiva está totalmente orientada hacia fuera, dado que es el producto de una función cerebral surgida con el fin de la simple autoconservación, es decir, del buscar alimento y cazar las presas. Por eso cada cual sabe de sí tan sólo desde este individuo, tal como se presenta en la intuición externa" (1986, Tomo II, p. 628). Esto nos ayuda a comprender por qué en la filosofía temprana de Schopenhauer la conciencia de la voluntad como la cosa en sí no pudo ser concebida gracias al conocimiento empírico, el cual está dirigido completamente hacia fuera, sino gracias al conocimiento mejor, que está dirigido completamente hacia dentro, ya que bajo esta cosmovisión ningún conocimiento que esté subordinado a la razón suficiente podría haber posibilitado tomar conciencia -desde el interior-de la voluntad como la cosa en sí. "Sólo cabe zafarse de este dilema gracias a mi filosofía, al ser la primera que coloca la auténtica esencia del hombre no en la conciencia, sino en la voluntad, que no está esencialmente ligada con la conciencia, sino que se relaciona con ella, esto es, con el conocimiento, como la sustancia con el accidente, como lo iluminado con la luz, como la cuerda con la caja de resonancia, y que llega a la conciencia desde dentro tal como el mundo exterior desde fuera" (1986, Tomo II, p. 258). 
La conciencia mejor es un estado de superación interior, el cual como tal forma parte de un momento de su metafísica, permaneciendo más tarde de otra forma, pero igualmente de un modo esencial en el sistema schopenhaueriano. Esta evolución se explica por el descubrimiento de la cosa en sí como voluntad, la cual no solo había sido esbozada y despachada por Locke, sino también tratada en toda su complejidad y rechazada de insoluble por Kant. La cosa en sí recibe en esta filosofía el nombre de "voluntad" y se le otorga una identidad cabal: "voluntad de vivir", "la cual es sitial y fuente del dolor". La esencia interior del hombre es $s u$ voluntad y también el organismo completo de cada cual. Desde esta perspectiva el cuerpo y la voluntad son idénti$\cos$. El modo cómo se representa empíricamente no es más que su propia objetivación. No es otra cosa que la imagen proveniente de la voluntad en el cerebro.

Ahora nos encontramos en condiciones de notar aquí un inusual, curioso y sorprendente intento: "Si ahora logramos, puesto que a fin de cuentas pertenecemos también nosotros a la esencia íntima del mundo, dándole la vuelta al principium individuationis, acercarnos a las cosas desde un lado y una vía completamente distinta, desde dentro y no únicamente desde fuera, y de ese modo dominarlas mediante el conocimiento en la clarividencia y la acción en la magia, entonces se produce, justo para este conocimiento cerebral, un resultado que era realmente imposible lograr en su propia vía. De ahí que tal conocimiento lo ponga en tela de juicio, ya que un resultado de esta clase sólo es comprensible metafísicamente; físicamente es una imposibilidad" (1986, Tomo IV, p. 362).

En El ensayo sobre las visiones de fantasmas, Schopenhauer sostiene que gracias al "órgano de los sueños" se manifiesta a la conciencia cerebral una forma intuitiva más inmediata y pura. Estas manifestaciones de la voluntad son fruto de un orden más profundo original e inmediato, el cual -desde esta filosofía- solo es posible por una vía metafísica: "La voluntad, como cosa en sí, está fuera del principii individuationis (tiempo y espacio), por el que los individuos son separados: los límites que éste crea no existen entonces en la voluntad. Esto explica, en lo que pueda alcanzar nuestra inteligencia cuando entramos en este dominio, la posibilidad de una acción directa entre individuos, independientemente de su proximidad o lejanía en el espacio" (1986, Tomo IV, p. 364). Esta forma de hechos tiene lugar en el "órgano de los sueños".

Volvamos al testimonio autobiográfico que hemos elegido como hilo conductor del presente ensayo sobre la despersonalización como metafísica vivencial de la voluntad de vivir. En el caso del joven Schopenhauer, fue la desolación de la vida, aquello que pareció captar el todo, es decir, el dolor como lo absoluto de la conciencia empírica, aquello que tendió posteriormente a la nada impersonal de la conciencia mejor (1985, Tomo I, pp. 34-35). La duplicidad de la conciencia en un sujeto que sufre pone de manifiesto la necesidad de salir de sí mismo, evadirse del yo empírico, cuando se pierde toda esperanza de mejorar la conciencia empírica o simplemente de hallar un consuelo en ésta. "En mis años de juventud hubo un período en que me esforzaba constantemente en colocarme en un punto de vista separado de mí mismo, para verme y describirme a mí mismo y a mis actos. Probablemente sería para ver de que me parecieran soportables" (1986, Tomo II, p. 480). La juventud es una época que 
con razón en este caso la llamaría ad hoc "edad metafísica", tomando la expresión de Comte, pero para señalar algo opuesto del positivista francés ${ }^{2}$. Edad metafísica que desde la cosmovisión schopenhaueriana adquiere su justo sentido, porque al estar desprotegida de fortificaciones intelectuales y recursos teóricos, se es inevitablemente más vulnerable al dolor. De este hecho se desprende según mi opinión que desde una perspectiva estética Schopenhauer la llame la "edad de la poesía": "En la juventud, domina la contemplación; en la edad madura la reflexión. Una es la edad de la poesía, otra de la filosofía. En la práctica, igualmente por la percepción, somos determinados por la juventud; más tarde, por la reflexión" (1986, Tomo IV, p. 582).

No es casual que el autor de Die Welt als Wille und Vorstellung haya comenzado su obra tomando la máxima de Rousseau: ¡Sal de la infancia amigo y despierta! (Sors de l'enfance, ami, réveille-toi!). La intuición es por un lado algo característico de la infancia prefilosófica, por lo que la máxima de Rousseau en Schopenhauer sería una cifra de lo contrario en la medida en que el verdadero conocimiento lo halló en la conciencia directa que se le dio en la intuición, es decir, en la percepción nueva y fresca, la cual no le fue transmitida, como se le enseñaba teóricamente el conocimiento abstracto y secundario. Por otro lado, es precisamente esta intuición aunada con las

2 El dolor y el miedo que le provocó al joven Comte el desorden revolucionario del siglo XIX lo llevó a refugiarse en la idea de "orden y progreso", que valga señalar es opuesta a la de Schopenhauer. Para Comte son las ideas las que determinan el orden social, razón por la cual se concentró en crear un nuevo sistema de ideas, y así desechar el de aquel tiempo que le parecía inadecuado y anticuado. Eliminó teóricamente éste y se abandonó definitivamente en la filosofía positiva, construyendo un colosal baluarte teórico, que lo denominó: "la ley de los tres estados", desde donde tanto él como su filosofía no volvieron a salir al mundo de la intuición. En este sentido, la filosofía de Schopenhauer resulta ser opuesta, en la medida en que es una mezcla especial de ser y dejar de ser joven. Sin embargo, a Comte le sucedió algo distinto, él tenía motivos suficientes para no retornar, para no recaer en esa "enfermedad crónica" que es la juventud, ya que "la ley de los tres estados" le proporciona la verdadera cura de esa etapa, que tanto para el individuo, es decir, él, como para la humanidad transcurre entre la infancia y la virilidad. Según Comte, el estado teológico se caracteriza por la búsqueda de las causas últimas y la esencia íntima de las cosas o conocimientos absolutos, los cuales hallan su respuesta en la existencia de seres sobrenaturales, sean éstas fuerzas impersonales, sean dioses múltiples, o sea finalmente un solo Dios (tres etapas: fetichismo, politeísmo, monoteísmo). El estado metafísico es solo una modificación del anterior, los seres sobrenaturales se convierten en entidades abstractas inherentes a las cosas, las cuales Comte considera en todo semejantes a la "virtud dormitiva" del opio. En este sentido, la postura entre el filósofo de Montpellier y el de Danzig sigue siendo opuesta. Comte es radical, el estado metafísico no es una verdadera negación del teológico, sino una simple modificación y el proceso es simplemente lineal, a base de substituciones, sin existir una verdadera síntesis circular. Esto lo lleva a condenar a gran parte de los filósofos ilustrados, aunque no todos, los acusa en su mayoría por haber provocado la revolución en lugar de establecer el orden y progreso, propio del estado positivo, que supone la renuncia al saber absoluto, y propone la búsqueda exclusiva de las leyes que explican los hechos. 
reflexiones posteriores de juventud, aquello que le permite despertar de la inconsciencia de la voluntad (1986, Tomo II, p. 509). Schopenhauer piensa que en la infancia se es capaz de contemplar el mundo y la naturaleza de las cosas de una manera objetiva, "poética", porque el conocimiento no está aún encadenado al querer avasallador de la voluntad (1986, Tomo IV, p. 570). Cuando se manifiesta la voluptuosidad en la pubertad y en el período de juventud, nace entonces el deseo de ser y alcanzar cada cosa, vivenciándose la voluntad como tal. El mundo ya no es una poesía objetiva, sino conciencia empírica, es el dolor de querer alcanzar dichas imágenes (1986, Tomo IV, p. 572). Sin embargo, tal dolor veremos que es el $\delta \varepsilon v ́ \tau \varepsilon \rho o \varsigma ~ \pi \lambda$ oṽ $\varsigma$ que posibilitará el despertar de la inocencia y de la ingenuidad propia de la infancia. Por mientras, es preciso señalar que al vivenciarse las cosas en este periodo sin mayor voluntad, se le confiere al mundo un valor armónico, que refleja el descanso de la mirada objetiva, la cual no ha sido perturbada por los tormentos provenientes de un querer alcanzarlas, ni ha sido, por consiguiente, afectada de tal modo por el dolor subjetivo que ello implica (1986, Tomo I, p. 444). Por esta razón, la máxima de Rousseau debe ser interpretada como un saber salir de la ingenuidad y lo ilusorio de la infancia, lo cual queda claramente expresado en la palabra "despertar". "Despertar" en el que se pondera la infancia de un modo esencial, al guardar relación con la lucidez, propia del conocimiento intuitivo característico de ella. En el ocaso de este período se es más vulnerable a padecer el dolor que proviene de la voluntad y, por lo mismo, se abre la posibilidad de salir de la inocencia y la ilusión en torno a la cual esta voluntad aparentaba estar ausente, posibilitando dicha vivencia tomar conciencia de ella. Ya sabemos entonces lo que hay detrás cuando Schopenhauer recuerda en primera persona que "sin haber completado la formación escolar, fui sobrecogido por la desolación de la vida". Corresponde ahora referirnos a un hecho puntal.

En 1803, Schopenhauer se acomoda a los deseos del padre y renuncia a ir al instituto de enseñanza media para seguir posteriormente una carrera universitaria. A cambio, se le ofrece la posibilidad de comenzar el aprendizaje del oficio de comerciante. Como premio a esta decisión se le permite acompañar a sus padres en un viaje no menor por Europa. Precisamente de esta fecha, 1804, data este testimonio personal. Cuando "al igual que Buda en su juventud" sale a conocer el mundo y es sobrecogido por la enfermedad, la vejez, el dolor y la muerte. Schopenhauer está recordando el conocido episodio bibliográfico del legendario Siddahrta Gautama. La leyenda cuenta que Bodhisattva (el que llegará a ser el Buda) logró, por méritos acumulados en sucesivas encarnaciones anteriores, nacer en el cuarto cielo de los dioses. Se dice que su historia comienza en los cielos. "Mira, desde lo alto, la tierra y considera el siglo, el continente, el reino y la casta en que renacerá para ser Buda y salvar a los hombres" (Borges 2003, p.10). En ese mismo acto elige a su madre, la reina Maya, que significa la fuerza mágica que crea el ilusorio universo, y a su padre Suddhodana, rey en la ciudad de Kapilavastu, al sur de Nepal. Según se cuenta, el legendario, recién nacido, anunció ser "el primero y el mejor". "Éste es mi último nacimiento; vengo a dar término al dolor, a la enfermedad y a la muerte" (Borges 2003, p. 10). El niño es llamado Siddharta, aunque también es conocido por el nombre de Gautama. Los intérpretes del sueño de Maya profetizaron que sería dueño del mundo, "un gran rey", por ejemplo, o 
redentor de éste. El padre de Gautama, rey del clan guerrero de los Säya, quiere solo lo primero, por lo que hace construir tres palacios para Siddharta, procurando criar a su hijo dentro del más ostentoso ambiente de un palacio, aislado del mundo exterior. Aislado, para excluirlo de toda cosa que pudiera revelarle la caducidad, el dolor o la muerte. No obstante, a los veintinueve años de edad, antes de hallar el camino hacia la iluminación, el príncipe decide salir en su carruaje del palacio. Recién entonces fue cuando presenció con espanto a un hombre cuyo pelo y cuyo cuerpo encorvado "no es como el de los otros". El hombre está apoyado en un bastón y su carne tiembla. Cuando le pregunta sorprendido a su cochero de qué se trata, éste le responde que es un anciano y que todos los hombres acaban siendo como él. En otra salida, Gautama observó a un hombre devorado por la lepra, su cochero le dijo que era un enfermo y que nadie está exento de caer en ello. Otro día vio un cadáver transportado en un féretro, le explican entonces que la muerte es la ley de todo lo que nace. En su última salida, Gautama pudo ver a un asceta, es decir, a esos hombres que se retiran a los bosques para evitar la acumulación de efectos kármicos ${ }^{3}$ y trascender el samsara. Fue entonces cuando el legendario personaje cree haber encontrado el camino.

El padre de Gautama quiso sustraer a su hijo de la realidad del mundo y del dolor, brindándole los goces de las más fastuosas comodidades que goza todo príncipe en un palacio. Sin embargo, diez años de ilusoria felicidad, "dedicado al goce de los sentidos en su palacio", no le impidieron a Gautama escoger su propio camino, salir del palacio y despertar del sueño de la vida al contemplar la vejez, la enfermedad y la muerte. De un modo similar que el padre de Gautama, Floris Schopenhauer quiere alejar a su hijo del mundo de la reflexión, para brindarle todas las comodidades y seguridades que le proporcionaría el estatus de comerciante que él mismo gozaba, hecho que Schopenhauer experimenta como una traba irreparable que le impide escoger su propio camino ${ }^{4}$. Indudablemente esta alma joven había decidido

3 El deseo es lo que origina el movimiento del ciclo de las transmigraciones, pues proporciona la acumulación de karman, en cada individuo, correspondiente a la medida en que sus acciones responden a la sed del deseo. El acallamiento de las pasiones proporciona en cambio un estado de absoluta serenidad, en el que deja de acumularse karman, de manera que se produce la desvinculación del ciclo transmigratorio.

4 Schopenhauer, Arthur (1978) Gesammelte Briefe, pp. 649-650 ("Sin embargo, ya desde antes de que transcurriese esta época, yo sentía una fuerte inclinación a seguir una carrera que tuviese que ver con el estudio y la erudición; por eso rogué a mi padre que no me obligase ser comerciante y me permitiera obedecer el dictado de mi voluntad. (...) Su innato respeto por la libertad le disuadió de imponerme su plan por la fuerza. Mas no tuvo reparos en recurrir a la astucia. Él sabía que yo estaba muy ansioso de ver mundo, y cuánto anhelaba visitar de nuevo a mi amigo francés. Por eso me notificó que la próxima primavera emprendería con su mujer un largo viaje de placer por buena parte de Europa y que yo podía tener ocasión de participar en ese soberbio periplo, recalando también en casa de mi amigo, con tal de que le prometiera que cuando volviésemos me consagraría por entero al oficio de comerciante; si por el contrario persistía en dedicarme al estudio, permanecería en Hamburgo aprendiendo latín. La elección quedaba en mis manos"). 
emprender el viaje con sus padres, mas el retorno fue inminente y luego de Holanda, Francia, Inglaterra, Bélgica, Suiza, Austria y diversas ciudades de la misma Alemania, tuvo que enfrentar su esclavizante promesa: “(...) Ahora tenía que habérmelas con un oficio que odiaba y con la más horrible de las servidumbres; cada vez me hallaba más convencido de que mi vida seguía un camino equivocado y que toda ella no era sino un gran error que yo creía irreparable" (1978, p. 651). Con todo, Schopenhauer se siente forzado a seguir un camino que padece como irreparable. No obstante ello, tras dos largos e interminables años, -luego de haber contemplado el mundo de un modo directo-, toma la decisión de abandonar el aprendizaje de comercio y comenzar a forjar el camino de su propia filosofía. Sin embargo, no deja tras esta decisión de contraer una deuda. El no haber cumplido con su padre, -de quien estuvo siempre agradecido-, es un hecho que queda demostrado en las dos extensas dedicatorias, con las cuales pensó consagrarle la primera edición eventual de Die Welt als Wille und Vorstellung. Surgiendo de inmediato la duda de si estos agradecimientos -que hoy se conservan en los Nachlaß (1985, Tomo II, p. 379)- son expresión de un afecto velado y el intento de darle posteriormente otra interpretación a la ruptura con el mundo paternal en una armonía y vuelta a las verdaderas raíces. Recordemos que es el joven de 17 años a quien el destino repentinamente "le arrebató al más amado y mejor padre, de golpe por una muerte cruel" (1978, p. 651), quien concluirá que este mundo ha sido la creación de un diablo "que llamó a las criaturas a la existencia para recrearse en la contemplación de su dolor". Analizar la incidencia de este hecho en la cosmovisión del joven Schopenhauer parece un hecho producente y acertado. Sin embargo, tales asociaciones no deben tentar a los críticos de Schopenhauer a seguir una vía psicoanalítica sesgada. Previendo ello, es deber nuestro detenernos ante dos aspectos fundamentales. En una neurosis diabólica del siglo diecisiete, Freud desarrolla un apartado especial para corroborar su tesis del "diablo como sustituto del padre", utilizando la historia del pintor Cristóbal Haitzmann (Freud 1924. p. 18). El caso se refiere a un pintor que vende su alma al diablo para ser librado de una honda melancolía causada por la muerte de su padre, depresión que resultaba ser un claro indicio del amor que sentía por él.

A primera vista, el hecho resultaba en extremo singular, en la medida en que este sujeto pactaba nada menos que con el demonio para sustituir, según Freud, al padre amado. Sin embargo, tal tesis es sustentada por el psicoanalista en el supuesto de que el padre de Cristóbal Haitzmann, se hubiese opuesto al hecho de que su hijo fuese pintor. Al incapacitar con antelación al hijo, el poder ganarse su sustento, habría incrementado la nostalgia del hijo hacia su padre, mirándolo ahora como protector ante sus necesidades de la vida. En lo que se refiere a las visiones, al contenido de las alusiones, son para Freud, manifestaciones de un querer sobreponerse a ello, eligiendo una forma de vida en la que se verá libre del cuidado de procurarse el sustento (Freud 1924, p. 21).

La historia de Cristóbal Haitzmann nos sirve para establecer una analogía entre el joven Schopenhauer y su padre. Si bien su caso no culmina en una "neurosis diabólica" como en Haitzmann, observamos, sin embargo, que igualmente en el origen y en la meta de su filosofía se produce una ruptura con el mundo. Ruptura que queda 
de manifiesto en los modos de conciencia de un sujeto que sufre. Me refiero a la temprana dualidad concebida por el joven Schopenhauer entre la conciencia empírica y la conciencia mejor, y cuyo potencial filosófico se evidencia claramente mediante el curso posterior de la negación de la voluntad de vivir, vía mediante la cual si bien compensa esta ruptura, tiende no obstante en su fin último a una nada impersonal. No niego que Henrich Schopenhauer haya inconscientemente extremado la valoración teórica de su hijo por el ideal ascético. Me refiero al rol esencial del querer, para elegir una forma de vida en la que se consiga librar teóricamente del cuidado de procurarse el sustento. Apelando a una comprensión integral es válido complementarnos con este aspecto. Sin embargo, seguir una vía psicoanalítica, basándonos únicamente en la relación padre e hijo, para comprender la evolución de un diablo al descubrimiento de la voluntad como la cosa en sí (das Ding an sich), es un camino que si deja de ser complementario, no solo resultaría ser sesgado, sino además un intento muy superficial.

Cuando consideramos a Schopenhauer ser el precursor de Freud, en la medida en que este último también creyó en el deseo y la voluntad como principios motores de la vida humana, no debemos olvidar que el fundador del psicoanálisis se apoya en un postulado muy clásico que se remonta a Descartes (el cual es opuesto al de Schopenhauer), que supone que la claridad del conocimiento termina por reformar el querer. Es decir, en la medida en que mis pulsiones, mis tendencias secretas aparezcan a la luz del entendimiento, es posible dominarlas, lo que significa simplemente que el conocimiento de uno mismo puede terminar por vencer. En vista de lograr esto último, el psicoanálisis nos conduce a una vivencia, a una experiencia interna, mediante la cual sea posible posteriormente reconocer el querer y las pulsiones secretas que existen dentro de nuestra alma. En dicha experiencia se intenta "habitarla, es decir, habitarnos con seguridad". Sin embargo, la vivencia metafísica schopenhaueriana es opuesta en este sentido a la del psicoanálisis, puesto que no admite yo alguno. Más aún, ésta implica una despersonalización. La vivencia que el filósofo tuvo de la interioridad, para situar a la voluntad en una dimensión metafísica, lo vuelve necesariamente extraño a él mismo. Por esta razón, no es casual que el órgano de los sueños (Traumorgan) haya sido considerado por él mismo como metafísica práctica, empírica o experimental de la voluntad como la cosa en sí. De este hecho se desprende nuestra especial consideración, dirigida a dimensionar los fenómenos irracionales presentes en el órgano de los sueños (Traumorgan), siguiendo una vía epistemológica que no traicione ni su misma metafísica ni las premisas conceptuales de su filosofar.

Por consiguiente, no negamos el rol significativo que puede cumplir una explicación que se complemente con referencias psicoanalíticas para indagar el caso y el curso final de la negación de la voluntad de vivir, pero reducir a una explicación psicoanalítica la voluntad como la cosa en sí, la cual exige el desprendimiento del yo e implica un volverse extraño a uno mismo, es una vía que diferiría en lo esencial de la desarrollada en el presente ensayo. Para Freud, los demonios son "malos deseos rechazados, ramificaciones de impulsos instintivos reprimidos" (Freud 1924, p. 3), son síntomas de una enfermedad demonológica, los cuales, -según él mismo recalca-, son meros objetos de la fantasía, esto "para quien cree en el psicoanálisis y no en los demonios" (Freud 1924, p. 33). Freud añade: "En realidad no se le apareció ningún 
diablo, el pacto completo que hizo con el diablo lo hizo sólo en su fantasía" (Freud 1924, p. 33).

Yo creo, en cambio, en el demonio de Haitzmann y del joven Schopenhauer, como fuentes de veracidad del sujeto que sufre -como metafísica vivencial de sus cosmovisiones- y no como fantasías, que al ser reconocidas como tales, quedan únicamente recluidas al ámbito de las visiones, alucinaciones, convulsiones, ausencias, pérdidas o, en general, - como suele suceder-, que quedan encubiertas, al ser subordinadas a los propios constructos mentales. Valga señalar que el mismo Schopenhauer intentó derribar estos últimos, definiendo y enfatizando el rol que juega la intuición en las concepciones filosóficas de la temprana juventud.

Ahora bien, cuando el Schopenhauer de 17 años recuerda que la verdad "clara y distinta" que provenía del mundo, se sobrepuso pronto a los dogmas judaicos, deben tenerse en cuenta dos hechos esenciales. El primero dice relación con el aprendizaje directo, al cual nos hemos referido anteriormente, y que en este caso alude a la experiencia de su viaje (1978, p. 650). El segundo hecho guarda directa relación con aquella verdad "clara y distinta" que provenía del mundo, al igual como le sucedió a Buda en su juventud, es decir, provenía a través de la vejez, la enfermedad y la muerte, las cuales remiten según el budismo, a la duhkha, que señala las tres manifestaciones donde se concentra el dolor humano. Si bien la enfermedad y la muerte señala dos de las formas del sufrimiento humano, debe tenerse en cuenta aquí, que la concepción de la vejez schopenhaueriana es ambigua respecto a la budista, la cual a partir del mencionado episodio del legendario Gautama deriva en una concepción optimista de ella. Se ve en la vejez a un hombre que se libera de la tiranía del querer y adquiere la serenidad contemplativa de quien ya no es incitado a actuar mediado por las pasiones gobernadas por el querer. La posición de Schopenhauer es ambivalente a este respecto, puesto que suele referirse a la vejez como un período decadente y triste, de desilusión, que si bien puede reconocerse la nada y la vanidad de todas las magnificencias de la vida, tendiendo este desengaño a la serenidad y a la calma de quien logra liberarse de las tiranías de la voluntad, todo ello, va aunado sin embargo con la decadencia física y la muerte en perspectiva.

La idea del sufrimiento (duhkha) corresponde a la primera de las Cuatro Nobles Verdades, aparecida en los Upanisads, de que toda la vida es dolor: "el nacimiento es dolor, el envejecimiento es dolor, la muerte es dolor; estar unido a lo que no se ama es sufrir, separarse de lo que se ama es sufrir, no obtener lo deseado es sufrir" (Lapuerta 1997, p. 244), lo que permite darnos cuenta que esta analogía es del todo coherente en relación a la toma de conciencia del sufrimiento humano. Es dicha conciencia del dolor, aquella verdad "clara y distinta", que provenía del mundo, la cual se sobrepuso pronto a los dogmas judaicos que le habían sido inculcados. Nótese aquí que cuando Schopenhauer habla de una verdad "clara y distinta", no debe ser asociable con el sentido de la expresión cartesiana "clara y distinta" (Descartes 1995. (45), p. 48). La duplicidad de la conciencia, que debe ser entendida como los modos que adquiere en un sujeto que sufre, es lo que precisamente posibilita más tarde tener conciencia de la voluntad como cosa en sí, hecho que, al mismo tiempo, le permite corroborar con un sustento metafísico, que la razón, de ningún modo, puede ser movida por ideas claras 
y distintas ${ }^{5}$, sino, por el contrario, por ideas confusas y oscuras. Descartes efectivamente se interroga por lo confuso que hay en cada uno, sin embargo, debe considerarse que lo hace a partir de ideas claras y distintas (Descartes 1966, p. 73). Esto podría llevarnos al equívoco de pensar que la mismísima verdad a la que se está refiriendo Schopenhauer podría estar inmersa en un engaño por el hecho de que su claridad y distinción, el carácter diáfano de su asombro y luego de su reflexionar está siendo impulsado por una voluntad irracional, oscura e indistinta. No olvidemos entonces que el descubrimiento de la voluntad fue antecedido por una conciencia mejor que se libraba de los dominios del querer y que fue así como logró su captación y puesto metafísico. En lo que se refiere a este caso, hemos visto que aquella verdad clara y distinta que le habló del mundo fue posible mediante una intuición, que se opone al conocimiento abstracto, discursivo de la razón, que ha sido tomada a servicio de la voluntad. Coherente con esto, cabe señalar que cuando Schopenhauer escribe estas palabras en 1834, está recordando tras ellas al joven de 17 años que fue, al cual la verdad clara y distinta que le habló del mundo, -que hemos visto era lisa y llanamente dolor-, era vivenciado espiritualmente ante todo de un modo metafísico. Dicha verdad provenía ya, sin embargo, de una voluntad inmersa en una idea metafísica abstracta que resultaba aún confusa y oscura. Confusión que él tratará de esclarecer en su oscuridad, a partir de una conciencia empírica que en su abandono se libra de los dominios del querer oscuro y perturbador. Con todo, cuando afirma que la verdad clara y distinta, es decir, el dolor que provenía del mundo, fue aquello que: "se sobrepuso a los dogmas judaicos que me habían inculcado", su resultado entonces fue: "que este mundo no podía haber sido la obra de un ser benévolo, sino más bien de un diablo que llamó a las criaturas a la existencia para recrearse en la contemplación de su dolor". Esta conclusión es resultado de dos hechos fundamentales. En la medida en que la voluntad no era reconocida aún como la quintaesencia del mundo, el dolor le parece a Schopenhauer origen y meta de la existencia humana. La intencionalidad de la maldad para Schopenhauer es evidente, pero aún no está ligada al deseo de una voluntad metafísica ciega, sino intencional, por eso añade de inmediato: "Sin duda, la existencia humana proclama el destino del sufrimiento: pues está profundamente inmersa en el sufrimiento, no se salva de éste, su curso y desenlace es sin excepción trágico: una cierta intencionalidad no es aquí algo para subestimar". El dolor, por consiguiente, no le parece fortuito, sino

En la cuarta regla para la dirección del espíritu, Descartes define su método. Sabemos que éste se reduce a cuatro reglas, presuponiendo el primer precepto una confianza absoluta en la razón; Descartes (1966), Discurso del método. Trad. José Rovira Armengol. Buenos Aires: Editorial Losada, p. 47 ("El primero consistía en no admitir jamás nada por verdadero que no conociera que evidentemente era tal; es decir, evitar minuciosamente la precipitación y la prevención, y no abarcar en mis juicios nada más que lo que se me presenta tan clara y distintamente a mi espíritu que no tuviera ocasión de ponerlo en duda"). Descartes acepta como verdadero aquello que aparece con absoluta evidencia, pero la evidencia se da únicamente en la intuición. De un modo opuesto a Schopenhauer, la intuición cartesiana en un acto puramente racional logra captar dichas ideas claras y distintas. 
intencional. Si éste no solo es origen sino meta de la existencia humana, entonces solo un diablo pudo haber efectuado la creación.

El Schopenhauer que abandona los dogmas judaicos, los abandona porque ve en el optimismo, no tanto una ilusión o ingenuidad, sino insensibilidad. Le resulta inaceptable que un Dios (Jehová) produzca este mundo colmado de necesidades y de aflicciones y que más encima se aplauda de sí mismo encontrando que todo es magnífico ${ }^{6}$. Eso lo encuentra inadmisible ${ }^{7}$. El hombre es la deformidad más cercana e inmediata, la más perfecta de las apariencias por él creada.

Se suele criticar la filosofía de Schopenhauer por su tendencia melancólica y desoladora, pero la adversidad que tal tendencia suscita nos hace ver que las fábulas que se crean y se transmiten, que se creen y temen sobre un futuro infierno, donde se paga con dolor los pecados cometidos en el mundo, no difiere tanto de este mismo. Dostoievski en El infierno y el fuego eterno. Reflexiones místicas ha definido el infierno como el sufrimiento de no poder amar (Dostoievski 1944). Se refiere a éste como un dolor moral tan intenso, que las almas atormentadas se regocijarían en las llamas, porque olvidarían mediante tal tormento físico, la tortura moral que les resultaría mucho más intensa que la del cuerpo. La humanidad, sumida en la inconsciencia de lo que significa "el no poder amar", no parecería habitar en un lugar muy distinto del infierno descrito por Dostoievski. El lugar del pecado ya tiene mucho de infierno. No solo en la esclavitud, en la crueldad, en las guerras, en los exterminios se revela lo peor del hombre, es el no poder amarnos de una manera real lo que ha terminado en convertirnos en "el demonio de nuestro prójimo". De un modo directo o indirecto, formal o empírico, el hombre ha desplegado su maldad en todos los tiempos. En todas sus variantes no constituye esto la excepción, sino la mayor parte de las veces la regla. Schopenhauer parece tener razón cuando afirma que la permanente injusticia que se ejercen los hombres exige la necesidad del Estado y la creación constante de las leyes más inimaginables, pero no parece constatar que nuestra maldad innata implica por lo mismo que todo esto se haya de algún modo ya institucionalizado. Por antonomasia, las fuerzas armadas son el más fiel reflejo de la crueldad, del odio y del terrorismo institucionalizado. Los pueblos atormentados que ayer fueron víctimas, alistan hoy a gente para convertirse en verdugos. La iniquidad extremada, la dureza del corazón y

Génesis 31 ("Y Dios vio que todas las cosas que había creado eran buenas").

La revolución metafísica, que describe, por ejemplo, Camus, llevada a cabo por Iván Karamasov, tiene sus orígenes en el rechazo al misterio y a "Dios en tanto principio de amor". Dicho rechazo es fruto de la misma insensibilidad que experimenta Schopenhauer, aunque los resultados serán opuestos, en cuanto Schopenhauer se manifiesta en contra de toda empresa que se decida por motivos. Camus se concentra, por el contrario, en explicar los motivos, por los cuales Iván simboliza el rechazo de la salvación. Iván condena a Dios en nombre de la justicia y hace de ella el motivo de su rebelión; sustituye el reino de la gracia por el de la justicia terrenal llevada a cabo por su persona, dándose el paso de la rebeldía a la revolución metafísica. (Camus, Albert 2003, El hombre rebelde. Trad. Josep Escué. Madrid: Alianza Editorial, p. 73). 
la crueldad directa no contenta a estos individuos en situaciones adversas con detener o matar, es decir, retener o eliminar, sino además menoscabar, torturar, humillar y destruir. La indiferencia es el yugo cultural que esconde nuestra responsabilidad histórica y la circunstancia temporal nos libra ilusoriamente de nuestra culpa. De un modo directo o indirecto, el hombre se transforma también en el demonio de su prójimo.

Cuando Schopenhauer reflexiona sobre la maldad humana producto de un querer metafísico, lanzando sus invectivas antioptimistas, no debemos olvidar que ellas son antecedidas por una cosmovisión optimista, la cual ha sido reconocida como tal en la vivencia de su insensibilidad: "no he de ocultar aquí que el optimismo, cuando no es un mero discurso irreflexivo de personas cuyo obtuso cerebro no encierra más que palabras, me parece no sólo absurdo, sino verdaderamente impío, pues es un sarcasmo contra los dolores sin cuento de la humanidad. No se olvide que la doctrina cristiana se inclina al pesimismo y que en los Evangelios las palabras 'mundo' y 'mal' se emplean como sinónimas" (1986, Tomo I, p. 447) ${ }^{8}$. El optimista que se maravilla ante una rosa, se maravilla al verla, mas ser esa rosa, es lo distinto. Ciertamente, las flores, las enredaderas son bellas, pero ellas también son una tendencia incesante sin fin, porque una satisfacción definitiva sería un punto de reposo. Sin embargo, la semilla será siempre punto inicial. Bajo esta cosmovisión, todo existente está en busca de su ser. La rosa vuelta hacia una luz que nunca será total, está atormentada también por el deseo. La enredadera figura aferrarse a un apoyo que en esencia parece nunca encontrar. No vayamos tan lejos y pensemos en las maravillas que el hombre mismo ha creado. Que la expresión instantánea al ver una de las siete maravillas del mundo sea una sonrisa, revela que viéndola puede ser una pirámide hermosa a la vista, pero ser el destino de los esclavos que las construyeron es otra cosa. Generaciones de hombres, con el trabajo de Sísifo, rodando, cargando piedra tras piedra, con los músculos tensos, con el temblor permanente en los brazos, sin el descanso, más que el necesario para seguir rindiendo, y sin siquiera tener la compensación de ver el trabajo terminado, trabajo que ya no es tal, sino destino que los ha cegado con el sol de frente, es eso lo que no ignora el pesimista.

El Schopenhauer que abandona los dogmas judaicos lo hace por antioptimismo: "en religión como en filosofía, el optimismo es un error fundamental que cierra la puerta a la verdad" (1986, Tomo II, p. 803). Pareciera que nos encontramos con el primer

8 Schopenhauer, Arthur (1986), Die Welt als Wille und Vorstellung II. Sämtliche Werke. Tomo II. Stuttgart/Frankfurt: Suhrkamp Taschenbuch Verlag. pp. 748-749 ("En definitiva, el optimismo es el ilegítimo autobombo del auténtico autor del mundo, la voluntad de vivir, que se refleja con agrado en sus obras: por consiguiente, no sólo una es una teoría falsa, sino también funesta. Pues nos presenta la vida como un estado deseable y la felicidad del hombre como fin suyo. Partiendo de ahí cada cual cree tener el derecho más justo a la felicidad y el goce: al no concedérsele tal derecho, como suele ocurrir, cree que se comete una injusticia con él y que se malogra el fin de su existencia, cuando es mucho más atinado considerar el trabajo, la privación, la miseria y el sufrimiento, todo ello coronado por la muerte, como el fin de nuestra vida"). 
filósofo de Occidente que funda un sistema que se identifica de un modo esencial con el pesimismo, hallando la evolución de la conciencia mejor, una hermandad con las sabidurías de Oriente. En este sentido, su filosofía amplía el horizonte de las cosmovisiones eurocéntricas, que creen poseer la única historia cultural de la razón. Schopenhauer pondera el valor de las religiones, no según la determinada concepción que tengan de la divinidad, sino en la visión general del mundo que ofrecen. Es decir, lo significativo no radica en si se trata de un monoteísmo, un politeísmo, un panteísmo o un ateísmo religioso, sino si alienta a una cosmovisión optimista o pesimista (Lapuerta 1997, p. 383). En la línea del brahmanismo upanisádico y el budismo, la doctrina cristiana presenta sensu allegorico la inanidad de los bienes terrestres, para volver la mirada hacia otra existencia contraria a la de este mundo. Schopenhauer piensa que este hecho encuentra su explicación sensu stricto en su filosofía: "Las grandes verdades que forman la esencia del cristianismo son el dogma del pecado original (afirmación de la voluntad) y el de la redención (negación de la voluntad); el resto no es, en su mayor parte, sino vestidura y accidentes. Debemos, pues, considerar a Jesucristo en general, como la personificación o símbolo de la negación de la voluntad de vivir" (1986, Tomo I, p. 550). Desde esta perspectiva, el Nuevo Testamento, es marcadamente pesimista, presenta el mundo como un "valle de lágrimas", puesto que considera la existencia misma como un mal. A raíz de ello, propone la redención o liberación de ella, adopta como símbolo un instrumento de suplicio y plantea la vida eterna como solución al problema de la existencia, que es el de la muerte (1986, Tomo I, p. 551).

Este artículo sobre la despersonalización como metafísica vivencial de la voluntad de vivir ha dejado de manifiesto que uno no puede abandonar el fenómeno en el que se halla inmerso, ni mediante la conciencia empírica ni mediante una conciencia que nos haya sido dada en la representación. Sin embargo, a través de fenómenos asociados a la despersonalización es posible vivenciar que no solo somos sujetos cognoscentes, sino que también en esa interioridad somos cosa en sí. La voluntad no solo está presente ahí, sino que constituye de un modo esencial dicha interioridad. Con todo, a causa de esta vivencia es posible hacernos autoconscientes de aquel querer de dimensiones metafísicas. Se nos abre así la posibilidad de captar la esencia íntima de las cosas, encarando a la voluntad, es decir, enfrentándose a uno mismo. He aquí cuando sale la voluntad de vivir de su anonimato, encuentra su identidad y comienza el curso del pensamiento que niega la voluntad de vivir.

Podemos entender ahora por qué la conciencia mejor reúne de un modo anónimo y fugaz todas las formas de negación de la voluntad, porque al no reconocer Schopenhauer este querer, como una determinación esencial de él, no podía entonces negarlo, sino tan solo esquivarlo. Como si fuera un elemento secundario y, por lo tanto, ajeno a su esencia íntima, el filósofo se retrae rumbo a una interioridad que niega las leyes de la identidad y del yo. No obstante, la vivencia de la voluntad siempre fue lo esencial. Utilizo la palabra vivencia antes que experiencia, para enfatizar que la asimilación del sufrimiento que reside en primer lugar en la imaginación realista, en los sueños o en las fantasías, cuyo contenido no tiene necesariamente constatación empírica en el mundo (piénsese, por ejemplo, el caso más extremo de ello como lo 
son el contenido de las alucinaciones visuales o auditivas), su padecimiento suele intensificar de sobremanera aquellos dolores que sí tienen constatación empírica o fáctica; es decir, cuyo contenido se puede constatar, tras razones suficientes en el mundo, como representación. Si bien la vivencia comprende la experiencia, su objeto no se define por una constatación empírica, comprendida tras razones suficientes, como sucede con la experiencia. A este hecho se refiere en todo su alcance la despersonalización como metafísica vivencial de la voluntad de vivir.

Resulta ineludible ahora reconocer tanto el dolor que evoluciona en el sufrimiento espiritual, -el cual se escinde de la realidad o del mundo como representación hasta la nulidad de la nada-, como a su vez el rol que cumple éste, transformándose en el $\delta \varepsilon v ́ \tau \varepsilon \varrho 0 \varsigma \pi \lambda$ oṽ $\varsigma$, que posibilita su compensación abstracta mediante el curso de la negación de la voluntad de vivir. Una despersonalización que conlleva en el camino inevitablemente un volverse extraño a uno mismo.

En este caso se trata de una disolución volente, que implica una pérdida de identidad, personalidad o yo. Es un proceso mental, caracterizado por la pérdida del sentido de afirmar el mundo como voluntad y representación. Igual como le sucede a ciertos pacientes psiquiátricos, que niegan todo lo existente, incluso a ellos mismos. Mas, la mayoría de las veces enfrentan entrópicamente el caos irracional del universo en sus cabezas.

La despersonalización como metafísica vivencial de la voluntad de vivir puede implicar la pérdida del sentido de uno mismo. La pérdida de las leyes que rigen el mundo como representación, se llama extrañamiento. El despersonalizado de la razón suficiente reconoce como fundamento tanto un extrañamiento de lo interno como de lo externo. Las coordenadas espacio-temporales pierden el sentido de la realidad. Del mismo modo que la conciencia empírica del mundo como representación pierde vigencia apareciendo ahora ante sus ojos como algo extraño, irreal y quimérico.

\section{Referencias bibliográficas}

\section{Obras de Schopenhauer}

Schopenhauer, Arthur (1978), Gesammelte Briefe. Bonn: Bouvier. (1985), "Der handschriftliche Nachlaß”, Frühe Manuskripte (18041818), Tomo I. München: Deutscher Taschenbuch Verlag.

(1985). "Der handschriftliche Nachlaß”. Kritische Auseinandersetzungen

(1809-1818), Tomo II. München: Deutscher Taschenbuch Verlag. (1985). "Der handschriftliche Nachlaß”. Die Manuskriptbücher der Jahre 1830-1852, Tomo IV-1. München: Deutscher Taschenbuch Verlag. (1986). Die Welt als Wille und Vorstellung I. Sämtliche Werke. Tomo I. Stuttgart/Frankfurt: Suhrkamp Taschenbuch Verlag. 
(1986), Die Welt als Wille und Vorstellung II. Sämtliche Werke. Tomo II. Stuttgart/Frankfurt: Suhrkamp Taschenbuch Verlag.

(1986), Kleinere Schriften. Sämtliche Werke. Tomo III. Stuttgart/ Frankfurt: Suhrkamp Taschenbuch Verlag.

(1986), Parerga und Paralipomena 1. Sämtliche Werke. Tomo IV. Stuttgart/Frankfurt: Suhrkamp Taschenbuch Verlag.

\section{BiBLIOGRAFÍA SECUNDARIA}

Borges, Jorge Luis/ Jurado, Alicia (2003), ¿Qué es el budismo? Madrid: Alianza Editorial.

Camus, Albert (2003), El hombre rebelde. Trad. Josep Escué. Madrid: Alianza Editorial.

Comte, Auguste (1980), Discurso sobre el espíritu positivo. Trad. Consuelo Berges. Madrid: Editorial Aguilar.

Descartes, René (1966), Discurso del método. Trad. José Rovira Armengol. Buenos Aires: Editorial Losada.

(1995), Los principios de la filosofía. Trad. Guillermo Quintás. Madrid: Alianza Editorial.

Dostoievski, Fedor (1944), Los hermanos Karamasov. Trad. Félix Azzati. Buenos Aires: Editorial Argonauta.

Freud, Sigmund (1924), "Eine Teufelsneurose im siebzehnten Jahrhundert”, Imago, Zeitschrift für Anwendung der Psychoanalyse auf die Geisteswissenschaften, Tomo IX, Cuaderno 1. Viena: Internationaler Psychoanalytischer Verlag.

Lapuerta. Francisco (1997), Schopenhauer a la luz de las filosofias de oriente, Barcelona: Editorial CIMS. 